\title{
sciendo
}

\author{
BULGARIAN ACADEMY OF SCIENCES
}

CYBERNETICS AND INFORMATION TECHNOLOGIES • Volume 21, No 1

Sofia $2021 \quad$ Print ISSN: 1311-9702; Online ISSN: 1314-4081

DOI: $10.2478 /$ cait-2021-0007

\section{Relating Student Engagement Indicators to Academic Performance Using Multiple Correspondence Analysis}

\author{
Ropo E. Ogunsakin, Sibusiso Moyo, Oludayo, O. Olugbara, Connie \\ Israel \\ ICT and Society Research Group, South Africa Luban Workshop, Durban University of Technology, \\ Durban, South Africa \\ E-mails: oreropo@gmail.com oludayoo@dut.ac.zardvcrie@dut.ac.zarconstancel@dut.ac.za
}

\begin{abstract}
Student engagement is an essential device for deepening learning, achieving learning outcomes, developing competencies, and improving academic performance in education settings. It is widely receiving increased attention among various scholars and higher education leaders. However, there are increasing concerns about the academic performance of students in higher education settings. The application of statistical data analytics for mining student engagement datasets is a candidate strategy for discovering essential indicators associated with academic performance. However, widely used data analytic methods like principal component analysis are ineffective when most of the indicators captured are categorical, making them inappropriate for establishing the weighty academic performance indicators. This study's objective was to investigate the application of multiple correspondence analysis to establish weighty student engagement indicators of academic performance. This study's findings have indicated that higher-order learning and student-staff interaction are weighty indicators that relate student engagement to academic performance.
\end{abstract}

Keywords: Academic performance, correspondence analysis, national survey, student behaviour, student engagement.

\section{Introduction}

Student engagement encompasses students' positive behaviors and experiences and is receiving more awareness among researchers, higher education authorities, and the public in recent years [1]. It is required because students acquire more skills when engaged; it is key to student satisfaction with learning and an essential ingredient of higher-order learning and student success [2]. It has become a more prominent phenomenon in studies on education quality because of its association with personal development and learning [3-6]. Student engagement has been recognized as a significant factor in understanding student dropout and improving throughput and retention rates. Its disengagement antonym is presupposed to be a gradual deviant 
behavior of students by becoming less committed to learning activities [7-9]. In addition, it has been directly linked to enhancing academic performance, which was explicated to be a strong predictor of student success and good behavior in schools [10]. Moreover, student engagement can be correlated with both healthcompromising and health-promoting behaviors [11]. Student engagement and academic performance are of prime importance to managers of education institutions as institutional productiveness is mostly assessed by academic achievement.

It is presumed that an understanding of student engagement indicators might help educators prevent adverse consequences due to the exhibited associations with the heterogeneity of outcomes. However, scientific methods and statistical data analytic tools have not yet gained prominent usage for learning about student engagement. This study seeks to broaden the scope of extant studies on student engagement and address a gap in the literature by applying Multiple Correspondence Analysis (MCA) as an Exploratory Data Analysis (EDA) method to relate student engagement indicators to academic performance. The South African Survey of Student Engagement (SASSE) tool has provided the 2018 dataset for this study. The SASSE is a customized archetype of the National Survey of Student Engagement (NSSE) that was initially developed in the United States of America. The NSSE was offered as a barometer for evaluating best practices in institutions of higher learning. It is one of the most famous resources on student engagement for assessing student participation in various educational activities [4]. The NSSE tool has been utilized by many countries across the world, including South Africa, the United States of America, Canada, Australia, the United Kingdom, and Switzerland.

This study's outcome can practically benefit managers of educational institutions and policymakers as both groups seek to understand better and address the inherent challenges of enhancing student development. This study has major significant contributions in two prominent areas. Firstly, identifying weighty indicators that might improve students' academic performance in a higher institution of learning is a unique contribution. The identified indicators can help higher education institutions' authorities be useful in assisting students to succeed. Secondly, MCA's application for the first time to mine a large and complex student engagement dataset is an essential contribution to data mining research. The paper is succinctly organized after providing the introductory message as follows. In Section 2, we provide details about related studies on student engagement and the MCA method. In Section 3, we present details of participants, the study dataset, and statistical analysis. In Section 4, we present study results, while Section 5 is a discussion of the results. Section 6 features concluding remarks with possible future research.

\section{Related literature}

There is substantial literature about student engagement, which has become a principal focus for institutional scholars in academic performance studies. Student engagement is frequently used to describe interest and enthusiasm for school, and it impacts on academic performance and behavior of a student [12]. The impact of 
student engagement on student achievement is no longer interrogated [13], but it is understood in different ways [14]. Student engagement involves the participation of students in school activities as well as student recognition and appreciation of school. Students who demonstrate active involvement in school activities are said to have high academic performance $[12,14]$ and positive attitudes [12]. However, disengaged students usually face the opposite situation, such as demonstrating low academic performance and showing negative behaviors. Besides, student engagement in the context of online learning is particularly challenging because online students seem to have fewer chances to be involved physically with their institutions, indicating the absence of institutional factors. Nevertheless, technology usage nurtures engagement policies based on active learning prospects that include partaking in collaborative study, easing student discussions, distributing resources energetically, and forming coursework with practical mechanisms [12]. Three elements of student engagement are behavioral engagement, cognitive engagement, and emotional engagement, which are defined by a multitude of factors associated with institutions, students, families, teachers, curricula, and learning resources [15]. Behavioral engagement is often defined as an engagement based on individuals' involvement in an institution's academic, social, and extracurricular activities.

Meanwhile, students' behavioral engagement behavior has been identified as a motivating factor that enhances more excellent academic performance and school retention. Cognitive engagement is an aspect of engagement that is focused on student investment in school and learning activities. The study on cognitive engagement is often concerned with how much students invest in learning and whether they are willing to work extra to better academic performance. The emotional engagement was identified as an engagement that focuses on how students identify with their institution. Identification with the institution means belonging, valuing, or feeling essential to the institution and appreciating academic performance in an institution's related outcomes.

In recent times, research has significantly advanced the understanding of student engagement that most scholars have conceptualized it as multi-dimensional [16]. Besides, a substantial quantity of studies has affirmed that educational technology can practically support online students' engagement [17]. In another development, Mayer [18] established that students acquire better knowledge from computerbased teaching, comprising words, graphics, and metaphors compared to words alone in orthodox learning. The incorporation of active learning in curricula can enable student engagement irrespective of the learning environment's conditions. In fact, active learning has been recognized as an instructional approach that involves students' active engagement with course materials through discussions, problemsolving, case studies, and other pragmatic teaching methods [19]. The NSSE tool has been used in many studies that link student engagement to positive student outcomes such as higher grades, retention, persistence, and completion [20, 21]. However, despite the increased interest in student engagement, the various statistical tools previously employed to analyze datasets associated with student engagement have been identified to present inherent limitations [16, 22, 23]. 


\subsection{Student engagement methods}

Many education scholars have viewed student engagement from different perspectives of student actions, teacher activities, and institution efforts. Different methods have been proposed in the literature for facilitating student engagement, and a typical example is flipped learning [24]. The method of NSSE has provided data to gain intuitive insight into the levels of student engagement [25]. The canon of literature has mentioned different methods that have been previously employed by researchers to investigate student engagement from a theoretical perspective and analyzed datasets associated with student engagement [26, 27]. More details about some of these methods have been covered by other authors [7, 17, 25, 28]. Based on the literature search, some of the methods previously employed to analyze student engagement datasets have some shortcomings and, as such, cannot bring forth the potential information that is needed for enhancing the academic performance of students. Consequently, there is a need to deploy more data analytic methods with an excellent capability to divulge confidential information contained in student engagement datasets.

\subsection{Multiple correspondence analysis}

The present study is focused on the application of Multiple Correspondence Analysis (MCA) to analyze a dataset associated with student engagement, even though there is no substantial literature on statistical methods in student engagement research. Although other disciplines such as health sciences, engineering, political science, and sociology [29-31] have extensively used the MCA method, it is rare in student engagement literature. For instance, Das and Sun [32] used MCA to explore the contributing factors regarding fatal run-off-road crashes in Louisiana. Kim and Yamashita [33] used the MCA method to investigate the characteristics of pedestrianinvolved collisions in Hawaii. Although we have acknowledged that there are a considerable number of studies on student engagement [24, 35], none of these studies have used graphical EDA techniques for the analysis of the South African Survey of Student Engagement (SASSE) to the best of our knowledge. MCA achieves coherent analysis by grouping indicators according to their similarity. Accurate results cannot easily be achieved by merely using a correlation-based method or classical regression analysis scheme.

A common finding from the literature has indicated different tools that researchers have utilized to assess student engagement. However, student engagement is always challenging to explain, which is not the focus of this study because it is a complex construct prejudiced by multilevel factors. Moreover, it remains fuzzy from the literature on student engagement factors that directly impact academic performance. This study focuses on relating student engagement indicators of NSSE to academic performance using the method of MCA. The research introduced in this paper serves as the first reference point to demonstrate MCA's useful application to determine the weighty engagement indicators that contribute to students' academic performance from a higher education institution. 


\section{Materials and methods}

\subsection{Participants}

The present study has utilized 1201 participating students from the Durban University of Technology (DUT) in South Africa. The student responses were drawn from the 2018 SASSE dataset at DUT. The descriptive statistics of participants based on faculty were obtained with the highest proportion of students from faculty of Accounting and Informatics (30.7\%), Management Sciences (24.2\%), Engineering and the Built Environment (16.5\%), Applied Sciences (10.2\%), Arts and Design (9.4\%) and Health Sciences (9.0\%). The student demography in terms of races is approximately $53.0 \%$ of sample were female students, $87.8 \%$ Black, 9.7\% Indian, $1.4 \%$ White, and $1.1 \%$ Colored students.

\subsection{Dataset}

This study has been conducted with 2018 SASSE data collected by DUT, one of the participating universities in the Siyaphumelela Network project (https://www.siyaphumelela.org.za/about.php). The project is being funded by the Kresge Foundation to improve data analysis at South African universities. The Siyaphumelela Network 2.0 version was recently launched on August 2020 through webinar due to the COVID-19 hiatus (https://www.saide.org.za/article.php?id=83). The participating universities are expected to develop capability in data analytics to harvest student data, create South African models of universities using data analytics to improve student learning outcomes, enlarge cadre of experienced professional data analytics and offer services, tools, and systems to foster student success based on scientific evidence from data.

SASSE dataset is an architype of NSSE dataset that reflects student participation in educationally purposeful activities, how students interact with lecturers, peers, and engage with diversity, how students perceive university environment, and demographic information about students. The NSSE instrument is among the most popular survey tools of student engagement. It has been used by many colleges and with four NSSE themes that were sub-divided into ten different indicators. The engagement indicators provide a summary of detailed information contained in student responses.

Each indicator is based on several levels of measurements that were organized coherently into four broad themes, as shown in Table 1 . In the current study, we have defined academic performance as measuring student achievement across various modules. It is customarily measured using the average score, high school graduation rate, annual standardized tests, and college entrance examinations. Meanwhile, the average score, which is a measure of academic performance in this study, is typically measured on a scale of zero to four, with a higher average score representing a higher academic performance. 
Table 1. Student engagement themes, indicators, and measures of SASSE

\begin{tabular}{|c|c|c|}
\hline Theme & Indicator & Measure \\
\hline \multirow[t]{4}{*}{$\begin{array}{l}\text { Academic } \\
\text { challenge }\end{array}$} & $\begin{array}{l}\text { Higher- } \\
\text { order } \\
\text { learning }\end{array}$ & $\begin{array}{l}\text { Amount of academic work that emphasized challenging learning } \\
\text { tasks, including applying learned information to practical problems, } \\
\text { identifying ideas and experiences, evaluating information from } \\
\text { other sources, and forming new ideas }\end{array}$ \\
\hline & $\begin{array}{l}\text { Quantitative } \\
\text { reasoning }\end{array}$ & $\begin{array}{l}\text { How often students engaged with numerical and statistical } \\
\text { information across curricula and used such information to examine } \\
\text { real-world problems, reach conclusions, and evaluate others' } \\
\text { concluded learning with peers }\end{array}$ \\
\hline & $\begin{array}{l}\text { Reflective } \\
\text { and } \\
\text { integrative } \\
\text { learning }\end{array}$ & $\begin{array}{l}\text { How often students connected prior knowledge, other modules or } \\
\text { subjects, and societal issues, considered diverse perspectives, } \\
\text { reflected on their views while examining others' views }\end{array}$ \\
\hline & $\begin{array}{l}\text { Learning } \\
\text { strategies }\end{array}$ & $\begin{array}{l}\text { How often students enacted basic academic success strategies, for } \\
\text { example, identifying important information in readings, reviewing } \\
\text { notes after classes, and summarizing subject material }\end{array}$ \\
\hline \multirow[t]{2}{*}{$\begin{array}{l}\text { Learning } \\
\text { with peers }\end{array}$} & $\begin{array}{l}\text { Collaborative } \\
\text { learning }\end{array}$ & $\begin{array}{l}\text { How often students collaborate with others when mastering difficult } \\
\text { materials, such as explaining materials to others, preparing for } \\
\text { examinations, working on group projects, and asking for help }\end{array}$ \\
\hline & $\begin{array}{l}\text { Discussion } \\
\text { with diverse } \\
\text { others }\end{array}$ & $\begin{array}{l}\text { How often students discussed with people who differ in terms of } \\
\text { economic background, religious belief, ethnicity, or political views } \\
\text { experienced with staff }\end{array}$ \\
\hline \multirow[t]{2}{*}{$\begin{array}{l}\text { Experiences } \\
\text { with staffs }\end{array}$} & $\begin{array}{l}\text { Student-staff } \\
\text { interaction }\end{array}$ & $\begin{array}{l}\text { How often students had meaningful and substantive interactions } \\
\text { with advisors and lecturers, such as discussing career plans, subject } \\
\text { material outside class or discussing their academic performance, and } \\
\text { working on student groups or committees }\end{array}$ \\
\hline & $\begin{array}{l}\text { Effective } \\
\text { teaching } \\
\text { practices }\end{array}$ & $\begin{array}{l}\text { The amount that lecturers emphasized student comprehension and } \\
\text { learning through clear explanations and organization, using } \\
\text { illustrative examples, and providing formative and useful feedback }\end{array}$ \\
\hline \multirow[t]{2}{*}{$\begin{array}{l}\text { Campus } \\
\text { environment }\end{array}$} & $\begin{array}{l}\text { Quality of } \\
\text { interaction }\end{array}$ & $\begin{array}{l}\text { How students rated their interactions with influential people in the } \\
\text { learning environment, such as academic staff, student support } \\
\text { services, peer learning support, and other students }\end{array}$ \\
\hline & $\begin{array}{l}\text { Supportive } \\
\text { environment }\end{array}$ & $\begin{array}{l}\text { The institution's amount emphasized students' help to persist and } \\
\text { learn through academic support programs, encouraged diverse } \\
\text { interactions, and provided social opportunities, campus activities, } \\
\text { wellness, health, and support for non-academic responsibilities }\end{array}$ \\
\hline
\end{tabular}

\subsection{Analysis}

Multiple Correspondence Analysis (MCA) has been applied in this study to analyze the student engagement dataset. MCA is a descriptive method designed to analyze simple two-way and multiway tables containing some measures of correspondence between rows and columns. It is a useful data analysis method and graphical demonstration of categorical data in massive and multifaceted datasets [32]. The graphical capability of MCA synopses the expression of associations among indicators without any underlying assumptions, which makes interpretation easier [32]. Moreover, MCA can look at multiple types of data and dimensions concomitantly, resulting in a sharp divergence to running innumerable bivariate investigations [32]. It is performed on an $N \times K$ indicator matrix in which $N$ is the number of data samples, and $K$ is the number of features describing the samples. The 
element in the cell $(n, k)$ of the indicator matrix consists of an individual information $n$ and category $k$ [36]. Related categories in MCA are to be found close together in Euclidean space, leading to clouds of data points that have comparable distributions [32]. Remarkably, MCA's output generates two-point clouds that are typically represented by a 2-dimensional graph [32]. The cloud of individuals is constructed on distances between individual information for an indicator, for which diverse categories of indicators have been selected [29]. Meanwhile, the squared distance between individuals related to each category is obtained in the case of each indicator $[32,36]$. An initial descriptive statistical analysis was performed to report the modalities of each indicator in the same direction. MCA method has been used in this study to explore indicators that associate student engagement to academic performance. On each of the factorial axes, we have obtained a discrimination measure to represent the intensity with which an indicator explained the axis. Moreover, we have analyzed the relative contributions of indicators and assessed which modalities are represented on the axes. The name of each MCA dimension was arbitrarily attributed according to the interpretation of its list of indicators. The proximities and locations of indicators, according to the axes, show their interdependences. A shorter distance between two indicators is an indication of a higher correspondence. In this study, MCA was performed using the R package FactoMineR included in the $\mathrm{R}$ software to benefit from the efficient implementation of the method.

\section{Results}

In this study, all the student engagement indicators captured by the SASSE dataset were utilized to perform MCA based on the explanation given in Section 3. The dataset contains 1201 rows (students) and ten columns (indicators) as proposed by NSSE. The graphical representations of MCA have helped to simplify the process of interpreting the associations among student engagement indicators. The indicator levels that share similar characteristics are located close together and well indicated in a 2-dimensional plot forming clouds of points. The associations among indicators in the first two dimensions are shown in Fig. 1 for all the engagement indicators. The individual information is compared to interpret the MCA plot and categories within the indicators by gauging the distances of map points. The closer the engagement indicators are to each other, the more they are related. The engagement indicators are colored, and lines show the distribution of each indicator along with the map. This result signifies that many of the engagement indicators possess a rough contribution to the MCA. However, it should be acknowledged that the closer an indicator is to the center of the map, the lesser its contribution to the eigenvalue of the respective dimension. This study's findings reveal that the engagement indicators that have contributed most to the first two dimensions are higher-order learning, supportive environment, student-staff interaction, and reflective and integrative learning because they are farthest from the center of the map. 


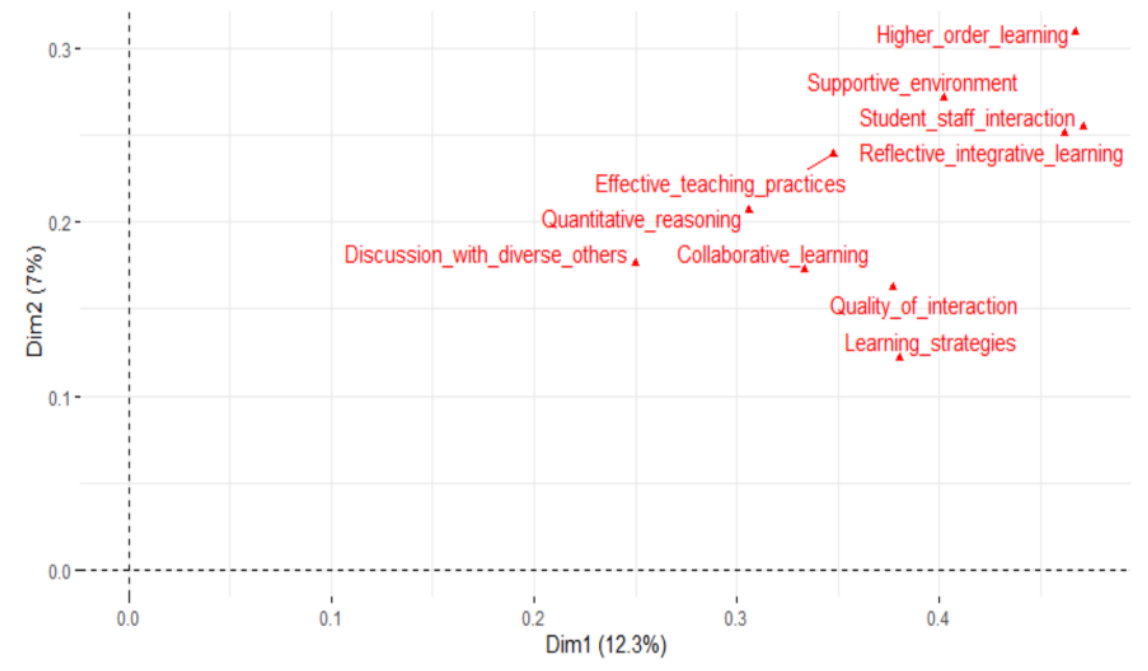

Fig 1. Plot of all engagement indicators

The magnitude of information related to each dimension is termed eigenvalue [37], with 0 or 1 indicating the total variance among indicators. Every point on the plot has its contribution to all dimensions, and the scale of the plot depends heavily on the volume of contributions of each dimension. In this study, we have observed that the first and second dimensions exhibited a greater eigenvalue than the other dimensions. The first and second dimensions have eigenvalues of 0.380 and 0.216 , respectively, as presented in Table 2 . Together, these two dimensions explain about $19 \%$ of the data variability. The low eigenvalues calculated for our dataset have demonstrated that the engagement indicators are heterogeneous. This heterogeneity may be a result of the random nature of the SASSE measures.

Table 2. Eigenvalue, percentage variance and cumulative percentage variance of top five dimensions

\begin{tabular}{|l|c|c|c|c|c|}
\hline \multirow{2}{*}{ Eigenvalues } & \multicolumn{5}{|c|}{ Dimension } \\
\cline { 2 - 6 } & 1 & 2 & 3 & 4 & 5 \\
\hline Eigenvalue & 0.380 & 0.216 & 0.147 & 0.122 & 0.117 \\
\hline Percentage of variance & 12.250 & 6.978 & 4.727 & 3.950 & 3.789 \\
\hline Cumulative percentage of variance & 12.250 & 19.228 & 23.956 & 27.906 & 31.695 \\
\hline
\end{tabular}

The model estimation has resulted in the formation of 10 principal dimensions, as shown in Fig. 2. The number of dimensions to be formed was estimated by the MCA method, and each dimension explains a certain amount of variance within the SASSE dataset. For instance, dimension 1 explains $12.3 \%$ of the dataset's total variance, while dimension 2 explains $7.0 \%$ of the dataset's total variance.

In Table 3, considering the coefficient of determination $\left(R^{2}\right)$ and $p$-value, all the indicators contributing to this study were identified. The order of presentation indicates the importance of each indicator. An association's strength is indicated by R2 parameter, with the value of 0 indicating no interrelation, and 1 indicates an extremely strong interrelation between the qualitative and MCA dimensions. The engagement indicators that were identified as contributing mostly to dimension 1 is "student-staff interaction", "higher-order learning", "reflective and integrative 
learning", and "supportive environment". In addition, these four indicators were consistently identified as mostly contributing to the second dimension.

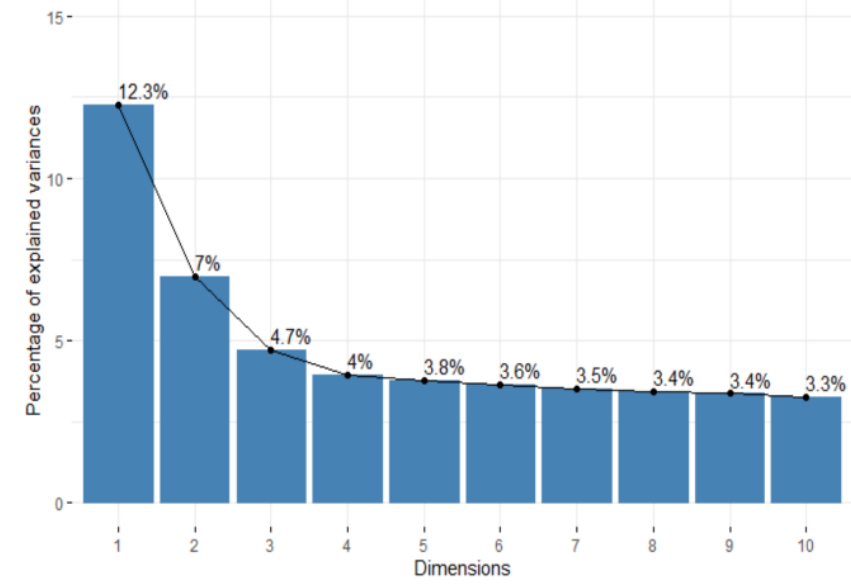

Fig 2. Indicator decomposition per dimension

Table 3. Statistical significance test for weighty indicators contributing to student engagement in the top 2 dimensions

\begin{tabular}{|c|c|c|}
\hline Dimension 1 & $R^{2}$ & $p$-value \\
\hline Student-staff interaction & 0.471 & $<0.001$ \\
\hline Higher order learning & 0.467 & $<0.001$ \\
\hline Reflective integrative learning & 0.462 & $<0.001$ \\
\hline Supportive environment & 0.402 & $<0.001$ \\
\hline Learning strategies & 0.380 & $<0.001$ \\
\hline Quality of interaction & 0.377 & $<0.001$ \\
\hline Effective teaching practices & 0.347 & $<0.001$ \\
\hline Collaborative learning & 0.333 & $<0.001$ \\
\hline Quantitative reasoning & 0.306 & $<0.001$ \\
\hline Discuss with diverse others & 0.249 & $<0.001$ \\
\hline Dimension 2 & $R^{2}$ & $p$-value \\
\hline Higher order learning & 0.309 & $<0.001$ \\
\hline Supportive environment & 0.271 & $<0.001$ \\
\hline Student-staff interaction & 0.253 & $<0.001$ \\
\hline Reflective integrative learning & 0.251 & $<0.001$ \\
\hline Effective teaching practices & 0.239 & $<0.001$ \\
\hline Quantitative reasoning & 0.206 & $<0.001$ \\
\hline Discussion with diverse others & 0.175 & $<0.001$ \\
\hline Collaborative learning & 0.171 & $<0.001$ \\
\hline Quality of interaction & 0.162 & $<0.001$ \\
\hline Learning strategies & 0.121 & \\
\hline
\end{tabular}

Fig. 3 shows the categories of engagement indicators in the top 2 dimensions in descending order of importance. The figure illustrates the levels with the most contributions, and a critical look at this table indicates that levels of very much Higher-Order Learning (HOL1) and very much Supportive Environment (SE2) are 
significantly linked to both dimensions. This result means a robust association between these two indicators in enhancing the academic performance of students.

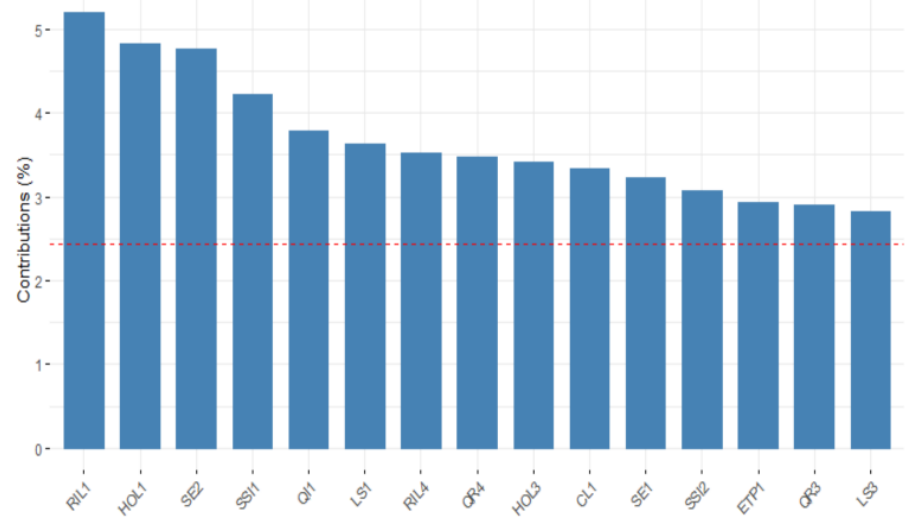

Fig 3. Contributions of levels in the first two dimensions

Furthermore, to substantiate whether the levels of a nominal indicator diverge significantly [37], we have created a $95 \%$ confidence ellipse for each engagement indicator. Some of the graphical outputs are shown in Fig. 4. The confidence ellipse provides a strong level of uncertainty correlated with the point location. It was observed based on this figure that all levels of indicators of never Collaborative Learning (CL4), very much Higher-Order Learning (HOL4), sometimes Reflective and Integrative Learning (RIL3), and very often Student-Staff Interaction (SSI4) imply no convergence of confidence ellipses. This finding implies that these indicators are fundamental to student engagement, and for students to improve their academic performance, they must be encouraged to participate in higher-order learning interventions. Besides, we have observed that various engagement indicators differ significantly based on the $95 \%$ confidence ellipses overlapping. Hence, we can faithfully conclude based on this finding that they have contributed equally to students' academic performance at the Durban University of Technology.

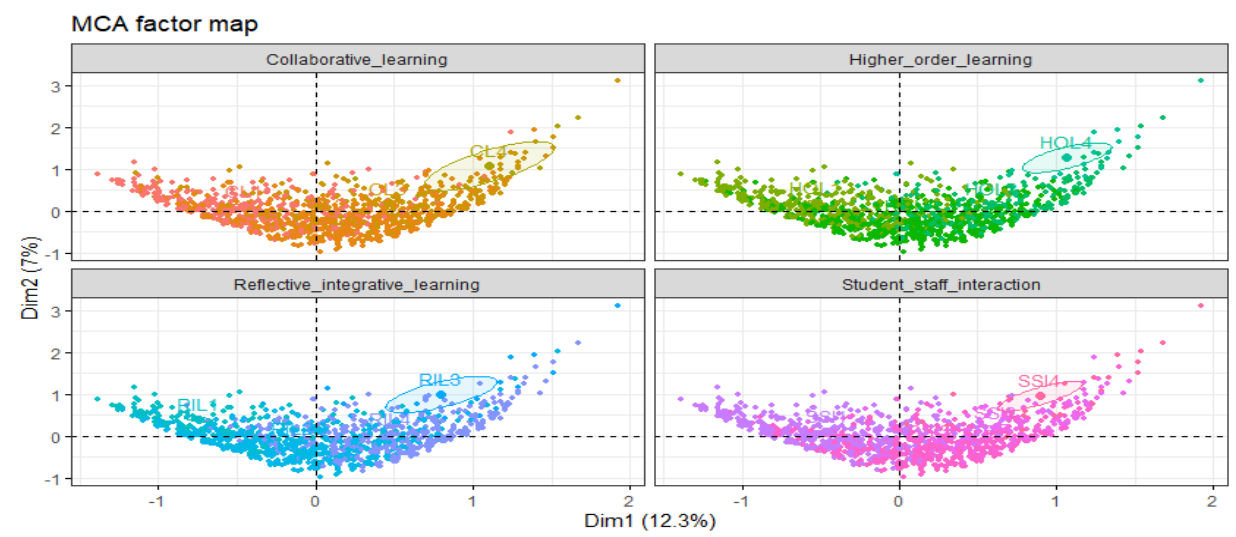

Fig 4. Factor map of indicator levels 
Fig. 5 shows the MCA biplot of the dataset under investigation, wherein the projections of row points onto directions defined by indicator vectors give an approximation up to a scaling indicator. The universal presentation of various levels of indicators in each portion of the 2-dimensional plot is given. The plot shows a global behavioral pattern in the student engagement dataset of which rows (students) are indicated by blue points and columns (categories) by red triangles. The distance between any row points or column points on the biplot gives a similarity or dissimilarity of two points. Row points with a similar profile are closed on the factor map, and the same argument holds for column points. The graphical plot provides an overall representation of categories with the highest contributions in each quadrant in the 2-dimensional plot, in which very much higher-order learning and sometimes student-staff interaction are making higher contributions. The result establishes that two major engagement indicators, which have contributed most to students' academic performance at the Durban University of Technology, are higher-order learning and student-staff interaction.

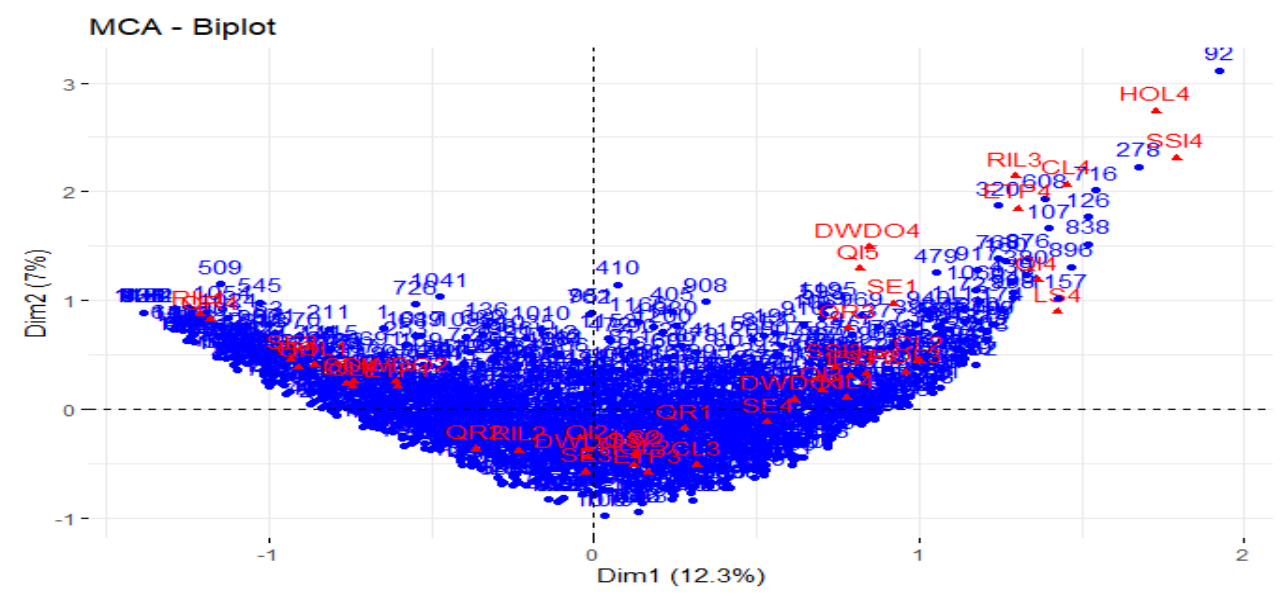

Fig 5. Biplot of student engagement dataset

\section{Discussion}

This study was designed to investigate student engagement indicators associated with students' academic performance at Durban University of Technology (DUT) and to evaluate whether there are subgroups with different pattern profiles. This study highlighted the engagement indicators that mostly contribute to variance in our MCA analysis and their main correspondences. These indicators could be considered the most relevant factors that can improve students' academic performance at DUT. This study can be replicated easily in other higher institutions of learning to establish a global comparison. For instance, higher-order learning is a concept that resonates with different types of learning activities and the amount of cognitive processing. It is a way to help students think divergently and convergently and not just memorize to improve their cognitive ability. Research has demonstrated that engaging students in the learning process increases their attention and motivates them to acquire higher- 
level critical thinking skills. Meanwhile, the results presented in this paper have demonstrated that we can use MCA to identify significant indicators that contribute to student academic performance. The total variance explained by the selected indicators is not high, with about $19 \%$ of the data dispersion recorded in this study. The eigenvalue correction can be recalculated to increase variances further using the Burt matrix to adjust for data dispersion [30,37]. MCA's unsupervised method can generate a more exciting combination of clouds with a tidy dataset, that is, a dataset with no missing values.

A 95\% confidence ellipse was constructed for the engagement indicators (Fig. 5) to substantiate whether the nominal indicator levels diverge significantly $[38,39]$. The confidence ellipse provides a strong level of uncertainty correlated with point location. It was observed that some levels of higher-order learning and studentstaff interaction are all associated with students' academic performance at DUT. Consequently, the two indicators can be regarded as pivotal for student engagement at DUT. Moreover, we have observed that various levels of those indicators differ significantly based on the $95 \%$ confidence ellipses overlapping. Thus, we can infer that they have contributed equally to the academic performance of students at DUT. The 15 highest contribution levels have been presented in Fig. 3 for coherency, which revealed various proximities combinations. Concerning the corresponding closeness of points, the classification of various clouds of points can be constructed. For instance, one combination corresponds to higher-order learning quite a bit as the contributing indicator. The dataset's global proximity behavioral patterns are revealed in the biplot with rows and columns representing blue points and red triangles, respectively, for the first two dimensions (Fig. 5). The way the quality of fit of the biplot is measured is exciting. Since it is well-known that regular (crisp) MCA seriously underestimates this measure. This finding is consistent with previous studies that have used MCA in other application areas, indicating that an indicator's contribution depends heavily on its levels. This, in turn, means that the greater the levels of an indicator, the greater its contribution to the variance of a cloud [31, 40]. There are many reasons that MCA is better than other parametric methods and why it is proposed in this study for relating student engagement indicators to academic performance. For instance, the corresponding closeness or disparity between more cases can be investigated concomitantly using MCA layout. In a scenario where more than two cases are to be investigated for interdependence, MCA's characteristics can provide colossal merit. This aspect is not investigated in the current study, but it may be a candidate recipe for future study. Despite other methods that can only pinpoint the weighty contributing indicators, MCA can link any other feasible associations among the contributing indicators. This point becomes the main distinguishing merit of MCA over other statistical methods, especially the parametric ones. Another important reason for using MCA is its ability to apply intuition to a large dataset using a detailed visualization functionality that intrinsically comes with the method $[29,40]$. Despite the inability to compute an estimated effect on indicators, MCA is still unique in identifying the significant combinations of desired indicators. For investigating the links between qualitative indicators, that is, the link between student engagement and academic performance, the study objective has been achieved. 
Besides, the quantification of categorical data can help further when modeling is possible with MCA in a more straightforward manner. This research's findings are practically useful to higher institutions' authority in determining student engagement's focal issues based on evidence from data. Moreover, they can aid authorities and policymakers in gaining intuition that can help comprehend weighty contributing indicators of student engagement, thereby leading to more astute policymaking. This study's key recommendation for higher education and education policymakers' authority is to promote student engagement, particularly in interventions associated with higher-order learning and student-staff interaction.

\section{Conclusion}

The present study has indicated that MCA represents an essential addendum to the list of scientifically sound methods that can be used to relate student engagement indicators to academic performance. Existing statistical analysis methods, particularly the parametric ones, have a fundamental underlying assumption and a pre-defined association between the outcome of interest and covariates. Such models could result in unreliable inferences, should one of the underlying assumptions be violated. In MCA's case, with no such underlying assumption, it has shown to be a useful statistical data analytic tool for mining information in a dataset associated with student engagement, as revealed in this study's findings.

The study findings have identified some exciting combinations among indicator levels used in the student engagement dataset. This study found that higher-order learning and student-staff interaction are essential indicators for relating student engagement to academic performance. This may imply that performing students engage in higher-order learning and interact well with staff. Moreover, we have observed that various responses of student engagement indicators differ significantly based on the overlapping of 95\% confidence ellipses. Consequently, any education institution interested in enhancing student academic performance should prioritize learning interventions pertaining to higher-order learning and student-staff interaction.

The one apparent limitation derives from this current study is its cross-sectional design, which means that temporal directions of associations between reciprocally connected indicators could not be defined. MCA's limit involves its mainly explorative role, which means further analysis is required to evaluate the key findings' role. Future research should focus on capturing student engagement indicators' cognitive and emotional aspects to inform policymaking on improving student academic performance. A vast shortage of studies focuses on student engagement's cognitive and emotional dimensions and factors influencing these dimensions. 


\section{References}

1. Q u i n, D. Longitudinal and Contextual Associations between Teacher-Student Relationships and Student Engagement: A Systematic Review. - Review of Educational Research, Vol. 87, 2017, No 2, pp. 345-387. https://doi.org/10.3102/0034654316669434.

2. Nguyen, T. D., C. Maris a, M. J a s o n. Understanding Student Behavioral Engagement: Importance of Student Interaction with Peers and Teachers. - The Journal of Educational Research, Vol. 111, 2018, No 2, pp. 163-174.

3. K u h, G. D., T. M. Cru c e, R. S h o u p, J. K in z i e, R. M. G o n y e a. Unmasking the Effects of Student Engagement on First-Year College Grades and Persistence. - The Journal of Higher Education, Vol. 79, 2008, No 5, pp. 540-563.

4. K u h, G. D., S. H u. The Effects of Student-Faculty Interaction in the 1990s. - The Review of Higher Education, Vol. 24, 2001, No 3, pp. 309-332. https://doi.org/10.1353/rhe.2001.0005.

5. Higuera-Mendieta, D. R., S. Cortés-Corrales, J. Quintero, C. GonzalezUribe. KAP Surveys and Dengue Control in Colombia: Disentangling the Effect of Sociodemographic Factors Using Multiple Correspondence Analysis. - PloS Neglected Tropical Diseases, Vol. 10, 2016, No 9.

6. Pike, G. R. Measuring Quality: A Comparison of Us News Rankings and NSSE Benchmarks. - Research in Higher Education, Vol. 45, 2004, No 2, pp. 193-208. DOI: 10.1023/b:rihe.0000015695.84207.44.

7. B a ng, H., M. Chang, C. Lee. Racial and Linguistic Status Differences in the Effect of Interscholastic Sport Participation on School Engagement and Academic Performance among High School Students. - Psychological Reports, Vol. 123, 2020, No 2, pp. 452-471.

8. Reschly, A. L., S. L. Christens on. Prediction of Dropout among Students with Mild Disabilities: A Case for the Inclusion of Student Engagement Variables. - Remedial and Special Education, Vol. 27, 2006, No 5, pp. 276-292. https://doi.org/10.1177/07419325060270050301.

9. D i L u 11 o, C., P. M c Ge e, R. Kr i e b e 1. Demystifying the Millennial Student: A Reassessment in Measures of Character and Engagement in Professional Education. - Anatomical Sciences Education, 2011, No 4, pp. 214-226. DOI:10.1002/ase.240.

10. Martinez, S., E. Mickey. The Effects of Participation in Interscholastic Sports on Latino Students' Academic Achievement. - Journal for the Study of Sports and Athletes in Education, Vol. 7, 2013, pp. 97-114. doi:10.1179/1935739713Z.0000000007.

11. G h a r i p o u r, M., L. T. A m b e r. Curriculum Development in Health and the Built Environment: Creating a Multidisciplinary Platform to Enhance Knowledge and Engagement. - ArchnetIJAR: International Journal of Architectural Research, 2020, pp. 2631-6862. DOI 10.1108/ARCH-09-2019-0212.

12. Marti n, F., D. U. B o 11 i g e r. Engagement Matters: Student Perceptions on the Importance of Engagement Strategies in the Online Learning Environment. - Online Learn, Vol. 22, 2018, pp. 205-222.

13. Trowler, V., P. Trowler. Student Engagement Evidence Summary. York, UK, Higher Education Academy, 2010.

14. A s h w i n, P., D. M c V it t y. The Meanings of Student Engagement: Implications for Policies and Practices. - In: The European Higher Education Area. A. Curaj, L. Matei, R. Pricopie, J. Salmi, P. Scott, Eds. Cham, Switzerland, Springer, 2015.

15. Fre d ri c k s, J. A., P. B l u m e n f e ld, J. Fri e d e l, A. P a ri s. School Engagement. - In: What Do Children Need to Flourish? Boston, MA, Springer, 2005, pp. 305-321.

16. S u n, Y., L. Ni, Y. Z h a o, X. L. S h e n, N. W a n g. Understanding Students' Engagement in MOOCs: An Integration of Self-Determination Theory and Theory of Relationship Quality. British Journal of Educational Technology, Vol. 50, 2019, No 6, pp. 3156-3174. 
17. Kahn, P., L. Everington, K. Kel m, I. Reid, F. W atkins. Understanding Student Engagement in Online Learning Environments: The Role of Reflexivity. - Educational Technology Research and Development, Vol. 65, 2017, No 1, pp. 203-218.

18. M a y e r, R. E. Using Multimedia for e-Learning. - Journal of Computer Assisted Learning, Vol. 33, 2017, No 5, pp. 403-423.

19. B onwe 11, C. C., J. A. E i s o n. Active Learning: Creating Excitement in the Classroom. ASHE-ERIC Higher Education Reports. Washington, DC, ERIC Clearinghouse on Higher Education, The George Washington University, One Dupont Circle, Suite 630, 1991, pp. 20036-21183.

20. Le a c h, L. Enhancing Student Engagement in one Institution. - Journal of Further and Higher Education, Vol. 40, 2016, No 1, pp. 23-47.

21. M c C l e n n e y, K., C. N. M a r t i, C. A d k in s. Student Engagement and Student Outcomes: Key Findings from. Community College Survey of Student Engagement. ERIC Number: ED529076, 2012, p. 6.

22. V e i g a, F. H. Assessing Student Engagement in School: Development and Validation of a FourDimensional Scale. - Procedia-Social and Behavioral Sciences, Vol. 217, 2016, pp. 813-819.

23. K i m, P. W. Ambient Intelligence in a Smart Classroom for Assessing Students' Engagement Levels. - Journal of Ambient Intelligence and Humanized Computing, Vol. 10, 2019, No 10, pp. 3847-3852.

https://doi.org/10.1007/s12652-018-1077-8.

24. B o n d, M. Facilitating Student Engagement through the Flipped Classroom Approach in K-12: A Systematic Review. - Computers \& Education, Vol. 151, 2020, 103819.

25. O 1 a d i p u p o, O., O. O l u g b a r a. Evaluation of Data Analytics-Based Clustering Algorithms for Knowledge Mining in Student Engagement Data. - Intelligent Data Analysis, Vol. 23, 2019, No 5, pp. 1055-1071. DOI: 10.3233/IDA-184254.

26. S k i n n e r, E. A., M. J. B e $1 \mathrm{~m}$ o n t. Motivation in the Classroom: Reciprocal Effects of Teacher Behavior and Student Engagement across the School Year. - Journal of Educational Psychology, Vol. 85, 2008, No 4, 571.

27. Fre d r i c k s, J. A., W. M c C o l s k e y. The Measurement of Student Engagement: A Comparative Analysis of Various Methods and Student Self-Report Instruments. - In: Handbook of Research on Student Engagement, Springer, 2012, pp. 763-782.

28. Zilvinski s, J., A. A. M a s s e ri a, G. R. P i ke. Student Engagement and Student Learning: Examining the Convergent and Discriminant Validity of the Revised National Survey of Student Engagement. - Research in Higher Education, Vol. 58, 2017, No 8, pp. 880-903.

29. G o g g in s, K. A., E. B r u c e, W. O d d s o n, L. B r e n t, R. E. T a m m y. Anatomical Locations for Capturing Magnitude Differences in Foot-Transmitted Vibration Exposure, Determined Using Multiple Correspondence Analysis. - Theoretical Issues in Ergonomics Science, 2020, pp. 1-15.

30. A b d i, H., D. V a 1 e n t i n. Multiple Correspondence Analysis. - In: N. Salkind, Ed. Encyclopedia of Measurement and Statistics. Thousand Oaks, CA, SAGE Publications, Inc., 2007, pp. 652-657.

31. Murtagh, F. Multiple Correspondence Analysis and Related Methods. Springer Science \& Business Media, 2007.

32. D a s, S., X. Sun. Association Knowledge for Fatal Run-Off-Road Crashes by Multiple Correspondence Analysis. - IATSS Research, Vol. 39, 2016, No 2, pp. 146-155.

33. K im, K., E. Y a m a sh it a. Corresponding Characteristics and Circumstances of CollisionInvolved Pedestrian in Hawaii. Transportation Research Record. - Journal of Transportation Research Board, Vol. 2424, 2008, pp. 18-24.

34. F a g n a n t, D. J., K. M. K o c k e $1 \mathrm{~m}$ a n. Motorcycle Use in the United States: Crash Experiences, Safety Perspectives, and Countermeasures. - Journal of Transportation Safety and Security, Vol. 7, 2015, No 1, pp. 20-39.

35. L e R o u x, B., H. R o u a n e t m. Multiple Correspondence Analysis. USA, SAGE Publications, Inc., 2010.

36. S i m p s o n, J. C., S. Wil s o n, N. C u r r e y. Motorcyclists' Perceptions and Experiences of Riding and Risk and Their Advice for Safety. - Journal of Traffic Injury Prevention, Vol. 16, 2015, No 2, pp. 159-167. 
37. J a 1 a y e r, M., M. Pou r-R ou h o 1 a m i n, H. Z hou. Wrong Way Driving Crashes: A Multiple Correspondence Approach to Identify Contributing Factors. - Traffic Injury Prevention, Vol. 19, 2018, No 1, pp. 35-41.

38. G r e e $\mathrm{n}$ a c r e, M. Correspondence Analysis in Practice. 3rd Edition. Barcelona, Spain, CRC Press, 2017. ISBN-13: 978-1-4987-3177-5.

39. Y ok ot a, K., W. K a z u mi, W. T a e k o, O. Y u s u ke, H. K a z u ki, F. Go ro. Crime Linkage of Sex Offences in Japan by Multiple Correspondence Analysis. - Journal of Investigative Psychology and Offender Profiling, Vol. 14, 2017, No 2, pp. 109-119.

40. S i v a s a $\mathrm{k}$ a r a n, S. K., V. B a 1 a s u b r a $\mathrm{m}$ a $\mathrm{n}$ i a n. Investigation of Pedestrian Crashes Using Multiple Correspondence Analysis in India. - International Journal of Injury Control and Safety Promotion, Vol. 27, 2020, No 2, pp. 144-155.

Received: 01.07.2020; Second Version: 29.11.2020; Accepted: 21.12.2020 